\title{
Modulation of defensive reflex conditioning in snails by serotonin
}

\author{
Vyatcheslav V. Andrianov ${ }^{1,2}$, Tatiana K. Bogodvid ${ }^{1,3}$, Irina B. Deryabina ${ }^{1}$, \\ Aleksandra N. Golovchenko ${ }^{1}$, Lyudmila N. Muranova ${ }^{1}$, Roza R. Tagirova ${ }^{1}$, \\ Aliya K. Vinarskaya ${ }^{4}$ and Khalil L. Gainutdinov ${ }^{1,2 *}$ \\ ${ }^{1}$ Laboratory of Neurobiology, Institute of Fundamental Medicine and Biology, Kazan Federal University, Kazan, Russia, \\ ${ }^{2}$ Group of Biophysics, Zavoisky Physical-Technical Institute, Russian Academy of Sciences, Kazan, Russia, ${ }^{3}$ Department of \\ Biomedical Sciences, Volga Region State Academy of Physical Culture, Sport and Tourism, Kazan, Russia, ${ }^{4}$ Laboratory of \\ Cellular Neurobiology of Learning, Institute of High Nerve Activity and Neurophysiology, Russian Academy of Sciences, \\ Moscow, Russia
}

\section{Highlights}

- Daily injection of serotonin before a training session accelerated defensive reflex conditioning in snails.

- Daily injection of 5-hydroxytryptophan before a training session in snails with a deficiency of serotonin induced by the "neurotoxic" analog of serotonin 5,7-dihydroxytryptamine, restored the ability of snails to learn.

- After injection of the "neurotoxic" analogs of serotonin 5,6- and 5,7-dihydroxytryptamine as well as serotonin, depolarization of the membrane and decrease of the threshold potential of premotor interneurons was observed.

OPEN ACCESS

Edited by: Onur Gunturkun,

Ruhr-University Bochum, Germany

Reviewed by:

Katharina Spoida,

Ruhr-University Bochum, Germany

Tiago Souza Dos Santos, Institut d'Investigacions Biomèdiques de Barcelona, Spain

*Correspondence: Khalil L. Gainutdinov kh_gainutdinov@mail.ru

Received: 08 June 2015 Accepted: 02 October 2015 Published: 23 October 2015

Citation: Andrianov W, Bogodvid TK, Deryabina IB, Golovchenko AN,

Muranova $L N$, Tagirova $R R$ Vinarskaya AK and Gainutdinov KL (2015) Modulation of defensive reflex conditioning in snails by serotonin.

Front. Behav. Neurosci. 9:279. doi: 10.3389/fnbeh.2015.00279
We studied the role of serotonin in the mechanisms of learning in terrestrial snails. To produce a serotonin deficit, the "neurotoxic" analogs of serotonin, 5,6- or 5,7-dihydroxytryptamine (5,6/5,7-DHT) were used. Injection of 5,6/5,7-DHT was found to disrupt defensive reflex conditioning. Within 2 weeks of neurotoxin application, the ability to learn had recovered. Daily injection of serotonin before a training session accelerated defensive reflex conditioning and daily injections of 5-HTP in snails with a deficiency of serotonin induced by 5,7-DHT restored the snail's ability to learn. We discovered that injections of the neurotoxins 5,6/5,7-DHT as well as serotonin, caused a decrease in the resting and threshold potentials of the premotor interneurons LPa3 and RPa3.

Keywords: serotonin, associative learning, identified neurons, membrane potential, threshold potential, snail

\section{INTRODUCTION}

One of the widespread and well-investigated transmitters in the nervous system is serotonin (Kandel and Schwartz, 1982; Sakharov, 1990; Crow, 2004; Gillette, 2006). Within a short period of time serotonin (5-HT) was identified as a neurotransmitter in both mollusks and mammals (Whitaker-Azmitia, 1999; Marinesco et al., 2004; Lee et al., 2009). The serotoninergic system plays an important role in the modulation of stress-induced excitability (arousal) and defensive behavior

Abbreviations: 5,6- and 5,7 DHT, 5,6- and 5,7- dihydroxytryptamine; 5-HTP, 5-hydroxytryptophan; SS, saline solution; 5-HT, serotonin. 
(Il-Han et al., 2010). The "5-HT neurons dispersed throughout the CNS of lophotrochozoan invertebrates (mollusks and leeches) are analogous to vertebrate 5-HT neurons concentrated in the raphe nuclei of the mid- and hindbrain: they innervate specific central pattern generators and other circuits of the CNS, receive feedback from them, and support general behavioral arousal" (Gillette, 2006). It has been shown that long-term facilitation in connections between sensory and motor neurons of the gill withdrawal reflex is mediated by 5 -HT and this form of synaptic plasticity was found to be a critical cellular mechanism in behavioral sensitization (Barbas et al., 2003; Hawkins et al., 2006; Hart et al., 2011). In connection to the discovery of the relationship between the level of 5-HT in the hemolymph of mollusks and the sensitization of reflexes (Levenson et al., 1999; Hernadi et al., 2008), a lot of experiments have been conducted using manipulation of the 5-HT system to investigate cellular analogs of learning (Lent and Dickinson, 1984; Gadotti et al., 1986; Glanzman and Krasne, 1986; JahanParwar et al., 1987; Vehosvzky et al., 1989; Mauelshagen et al., 1996; Kemenes, 1997; Malyshev et al., 1997; Shevelkin et al., 1997; Gainutdinov et al., 1999; Balaban, 2002; Burrell and Sahley, 2005; Jing et al., 2009). It was found that the injection of the neurotoxin 5,7-DHT led to a significant decrease in the withdrawal reflex caused by tail shock and inhibited the heterosynaptic facilitation between the sensory neuron and the subsequent cells in Aplysia (Glanzman et al., 1989). Balaban et al. (1987) showed that the pairing of food presentation and electrical stimulation didn't result in changes in responses to food in 5,7-DHT-injected snails, whereas in vehicle-injected snails defensive reactions were observed. Furthermore, injection of 5,7-DHT led to the disruption of long-term sensitization in Aplysia (Glanzman et al., 1989) and in snails (Balaban and Bravarenko, 1993; Gainutdinov et al., 1999). At the same time, it has been shown that although the intensity of the conditioning strongly decreases in leeches after depletion of serotonin by $5,7-$ DHT, they didn't lose the ability to learn (Burrell and Sahley, 1999). Thus, a considerable wealth of experimental material has been accumulated which points to the association between the functioning of the 5-HT- system of mollusks and their ability to learn (in behavioral experiments). However, the questions regarding to the specific mechanisms (and/or pathways) of 5HT participation in associative learning and the role of specific neurons in these processes remain open. These findings and questions motivated us to investigate the role of 5-HT in the mechanisms of learning by behavioral and electrophysiological methods, using the "neurotoxic" analogs of serotonin 5,6/5,7DHT, and the precursor of 5-HT syntheses, 5-hydroxytryptophan (5-HTP).

\section{MATERIALS AND METHODS}

\section{Experimental Animals}

For the experiments, the terrestrial snails Helix lucorum from the Crimean population, were used. The nervous system of these snails has been well described (Schmalz, 1914; Kilias, 1985; Balaban, 1993).
All experimental procedures are in compliance with the Guide for the Care and Use of Laboratory Animals published by the National Institutes of Health and Directive 2010/63/EU of the European Parliament and of the Council of 22 September 2010. Snails were stored asleep. Prior to the experiments, the snails were kept for no less than 2 weeks in a glass terrarium in a humid atmosphere at room temperature (each group in a separate terrarium) (Article 33 of Directive 2010/63/EU). All groups were housed in separate terrariums which were kept together all the time in the same room under the same conditions. The electrophysiological measurements were carried out in isolated preparations the day after training. Prior to the preparation procedure, snails were anesthetized (Article 14 of Directive $2010 / 63 / \mathrm{EU}$ ) by $30 \mathrm{~min}$ of immersion in water mixed with ice.

\section{Drugs}

\section{5,6/5,7-DHT}

In the experiments the "neurotoxic" analogs of serotonin 5,6and 5,7-dihydroxytryptamine (5,6/5,7-DHT) were used. Their effects on defensive reflex conditioning of snails and the electrical characteristics of premotor interneurons were investigated. They selectively destroy the 5-HT elements in the nervous system, particularly in nerve terminals, thus decreasing the level of 5HT (Gadotti et al., 1986; Glanzman and Krasne, 1986; Hernádi et al., 1992). 5,6-DHT (Sigma) was injected into snails twice at doses of $15 \mathrm{mg} / \mathrm{kg}$ with an interval of 7 days for a total dose of $30 \mathrm{mg} / \mathrm{kg}$. 5,7-DHT (Sigma) was injected into snails once at a dose of $20 \mathrm{mg} / \mathrm{kg}$ (Balaban et al., 1987). The neurotoxins were dissolved in $0.1 \mathrm{ml}$ of saline solution (SS). In addition, ascorbic acid was added to the solution as an antioxidant to achieve a concentration of $0.1 \%$. The injection of $0.1 \mathrm{ml}$ of SS (with the addition of ascorbic acid to achieve a concentration of $0.1 \%$ ) was used as a control. The injection of only 5,6-DHT without training served as an alternative control. One month after the injection of 5,6/5,7-DHT the 5-HT-containing neurons were selectively labeled with brown pigmentation, pointing to capture of 5,6/5,7-DHT by these cells. This phenomenon has been very well described earlier (Glanzman and Krasne, 1986; Balaban et al., 1987; Vehosvzky et al., 1989). Therefore, we did not take photos of the off-labeled cells.

\section{5-HT}

In another series of experiments the influence of serotonin (5HT) on defensive reflex conditioning in snails and the electrical characteristics of premotor interneurons was investigated. 5-HT (Sigma) was injected into snails daily $1 \mathrm{~h}$ before a training session at a dose of $10 \mathrm{mg} / \mathrm{kg}$. $5-\mathrm{HT}$ was dissolved in $0.1 \mathrm{ml}$ of SS, in addition ascorbic acid was added to the solution as an antioxidant to achieve a concentration of $0.1 \%$. The injection of $0.1 \mathrm{ml}$ of SS (with the addition of ascorbic acid to achieve a concentration of $0.1 \%$ ) was used as a control.

\section{5-HTP}

In a third series of experiments the influence of the precursor to 5-HT synthesis 5-hydroxytryptophan (5-HTP) on defensive reflex conditioning in snails and the electrical characteristics of premotor interneurons was investigated. 5-HTP (Sigma) was 
injected into snails daily $1 \mathrm{~h}$ before a training session at a dose of $10 \mathrm{mg} / \mathrm{kg}$. 5 -HTP was dissolved in $0.1 \mathrm{ml}$ of SS, in addition ascorbic acid was added to the solution as an antioxidant to achieve a concentration of $0.1 \%$. The injection of $0.1 \mathrm{ml}$ of SS (with the addition of ascorbic acid to achieve a concentration of $0.1 \%)$ was used as a control.

\section{Experimental Groups}

In the experiments we used the following groups of animals:

\section{Group 1: Defensive Reflex Conditioning}

Snails were trained to execute the defensive reflex on tapping on the shell (Balaban, 1993; Gainutdinova et al., 2003). Tapping on the shell (2 times) was used as a conditioned stimulus, which under normal conditions doesn't produce any defensive reaction in a snail. As an unconditioned stimulus a puff of air into the lung cavity orifice (pneumostome) was used, which produces the defensive reaction of pneumostome closure in animals. Only a complete closure of the pneumostome was taken as a "positive reaction" to the stimulus. Combinations of stimuli were presented with a random interval that ranged from 2 to $4 \mathrm{~min}$ (to prevent the elaboration of a conditioned reflex to time). The defensive reflex was trained according to 2 protocols:

(1) snails which were trained to execute the defensive conditioned reflex on tapping on the shell according to the first protocol $(n=19)$. Defensive conditioned reflex elaboration was developed over a 3 day period as a result of presentation of 150-170 pairs of the conditioned and unconditioned stimuli: this protocol consisted of 2 daily sessions each of them consisting of 30 combinations. The conditioned stimulus was presented by double tapping on the shell with $1.5 \mathrm{~g}$ force;

(2) snails which were trained to execute the defensive conditioned reflex on tapping on the shell according to the second protocol $(n=10)$. Defensive reflex elaboration was developed over a 6-7 day period as a result of the presentation of 300-350 combinations of the conditioned and unconditioned stimuli: this protocol consisted of 2 daily sessions of 30 and 15 combinations where the conditioned stimulus was presented by double tapping on the shell with $1.0 \mathrm{~g}$ force;

(3) snails of active control for the defensive conditioned reflex which received identical presentation of the conditioned and unconditioned stimuli, but in an unpaired combination $(n=18)$.

\section{Group 2: Effects of 5-HT and 5-HT Neurotoxins on Defensive Reflex Conditioning}

(1) snails which were trained to execute the defensive conditioned reflex on tapping on the shell according to the first protocol after injection of 5-HT $(n=7)$, snails were injected daily $1 \mathrm{~h}$ before a training session with 5 -HT at a dose of $10 \mathrm{mg} / \mathrm{kg}$ dissolved in $0.1 \mathrm{ml}$ of SS;

(2) snails which were injected with 5 -HT, but not trained $(n=$ 6), snails were injected daily with $5-\mathrm{HT}$ at a dose of $10 \mathrm{mg} / \mathrm{kg}$ dissolved in $0.1 \mathrm{ml}$ of SS;
(3) snails which were trained to execute the defensive conditioned reflex on tapping on the shell according to the first protocol after injection of $0.1 \mathrm{ml}$ of SS $(n=16)$, the injection of SS was used as a control;

(4) snails which were trained to execute the defensive conditioned reflex on tapping on the shell according to the first protocol on the next day after the second injection of "neurotoxic" analog of serotonin 5,6-DHT $(n=8)$, and 1 week after the second injection of 5,6-DHT $(n=8)$, 5,6-DHT (Sigma) was injected into snails twice at doses of $15 \mathrm{mg} / \mathrm{kg}$ with an interval of 7 days for a total dose of $30 \mathrm{mg} / \mathrm{kg}$. 5,6-DHT was dissolved in $0.1 \mathrm{ml}$ of SS;

(5) snails which were injected by "neurotoxic" analog of serotonin 5,6-DHT, but not trained $(n=26), 5,6-\mathrm{DHT}$ (Sigma) was injected into snails twice at doses of $15 \mathrm{mg} / \mathrm{kg}$ with an interval of 7 days for a total dose of $30 \mathrm{mg} / \mathrm{kg}$. 5,6-DHT was dissolved in $0.1 \mathrm{ml}$ of SS.

\section{Group 3: Common Effects of 5-HTP and 5,7-DHT on Defensive Reflex Conditioning}

(1) snails which were trained to execute the defensive conditioned reflex on tapping on the shell according to the second protocol after the daily injection of the precursor of 5-HT syntheses, 5-HTP $(n=8)$, snails were injected daily $1 \mathrm{~h}$ before a training session with 5 -HTP at a dose of $10 \mathrm{mg} / \mathrm{kg}$ dissolved in $0.1 \mathrm{ml}$ of SS;

(2) snails which were trained to execute the defensive conditioned reflex on tapping on the shell according to the second protocol after injection of SS in volume $0.1 \mathrm{ml}$ $(n=12)$, the injection of SS was used as a control;

(3) snails which were trained to execute the defensive conditioned reflex on tapping on the shell according to the second protocol on the next day after the injection of 5,7-DHT ( $n=8), 5,7$-DHT (Sigma) was injected into snails once at a dose of $20 \mathrm{mg} / \mathrm{kg}$. 5,7-DHT was dissolved in $0.1 \mathrm{ml}$ of SS;

(4) snails which were trained to execute the defensive conditioned reflex on tapping on the shell according to the second protocol after the daily injection of 5-HTP before each training session to animals which had previously been injected by "neurotoxic" analogs of serotonin 5,7-DHT $(n=10)$. 5,7-DHT (Sigma) was injected into snails once 5 days before the training session at a dose of $20 \mathrm{mg} / \mathrm{kg}$, snails were injected also daily $1 \mathrm{~h}$ before a training session with 5-HTP at a dose of $10 \mathrm{mg} / \mathrm{kg}$. 5,7-DHT and 5-HTP were dissolved in $0.1 \mathrm{ml}$ of SS.

\section{Group 4: Effects of 5-HT and 5-HT- Neurotoxins on the Electrical Characteristics of Premotor Interneurons in Snails after Defensive Reflex Conditioning}

(1) registration of the electrical characteristics of premotor interneurons in snails which were trained to execute the defensive conditioned reflex on tapping on the shell according to the first protocol after injection of 5-HT ( $n=$ 7 ), snails were injected daily $1 \mathrm{~h}$ before a training session with 5 -HT at a dose of $10 \mathrm{mg} / \mathrm{kg}$ in $0.1 \mathrm{ml}$ of SS; 
(2) registration of electrical characteristics of premotor interneurons of snails which were injected with 5-HT, but not trained $(n=6)$, snails were injected daily with 5-HT at a dose of $10 \mathrm{mg} / \mathrm{kg}$ in $0.1 \mathrm{ml}$ of SS;

(3) registration of the electrical characteristics of premotor interneurons in snails which were trained to execute the defensive conditioned reflex on tapping on the shell according to the first protocol on the next day after the second injection of 5,6-DHT $(n=8)$, and 1 week after the second injection of 5,6-DHT $(n=8), 5,6$-DHT (Sigma) was injected into snails twice at doses of $15 \mathrm{mg} / \mathrm{kg}$ with an interval of 7 days for a total dose of $30 \mathrm{mg} / \mathrm{kg}$. 5,6-DHT was dissolved in $0.1 \mathrm{ml}$ of SS;

(4) registration of the electrical characteristics of premotor interneurons in snails which were injected by 5,6-DHT, but not trained ( $n=26)$, 5,6-DHT (Sigma) was injected into snails twice at doses of $15 \mathrm{mg} / \mathrm{kg}$ with an interval of 7 days for a total dose of $30 \mathrm{mg} / \mathrm{kg}$. The neurotoxin was dissolved in $0.1 \mathrm{ml}$ of SS;

(5) registration of the electrical characteristics of premotor interneurons in snails which were trained to execute the defensive conditioned reflex on tapping on the shell according to the first protocol $(n=19)$.

\section{Intracellular Recording}

The nervous ring was immersed in a saline solution of the following composition: $\mathrm{NaCl}-80 \mathrm{mM}, \mathrm{KCl}-4 \mathrm{mM}, \mathrm{CaCl}_{2}-$ $10 \mathrm{mM}, \mathrm{MgCl}_{2}-6 \mathrm{mM}, \mathrm{NaHCO}_{3}-5 \mathrm{mM}$ (or Tris- $5 \mathrm{mM}$ ), $\mathrm{pH}-7.6-7.8$. The electrical characteristics of the withdrawal interneurons of the snail's pneumostome closure reflex LPa3 and RPa3 (Balaban, 1993, 2002) were analyzed. The recordings of the electrical characteristics were carried out on the day after training. The measurements were conducted at room temperature $\left(18-21^{\circ} \mathrm{C}\right)$ using intracellular glass microelectrodes with a resistance $10-30 \mathrm{MOm}$ filled with $2.5 \mathrm{M} \mathrm{KCl}$. The following parameters of the nervous cells were studied: resting membrane potential (the initial value prior to the onset of a number of tactile or electrical stimulations) $-\mathrm{Vm}$, and the threshold of action potential generation (threshold potential) Vt. The measurements of the electrical characteristics of the premotor (withdrawal) interneurons were conducted in preparations of snails from all series of experiments.

Since the premotor withdrawal interneurons LPa3 and RPa3 are silent in normal conditions, to generate action potentials in the isolated preparations we applied a depolarizing square-wave form electrical current through the recording microelectrode into the cell for $1 \mathrm{~s}$. For stimulation the minimal current strength for the generation of action potentials was selected; it varied from 1.7 to $3.5 \mathrm{nA}$.

\section{Data Analyses}

The results are shown as mean \pm SEM. The unpaired Student's $t$-test and non-parametric Mann-Whitney test were used for comparison between two groups. One-Way ANOVA followed by the Tukey post-hoc test and a repeated Two-Way ANOVA were used for comparison between three- or more statistical groups. Independent $t$-tests and the Tukey post-hoc test were used to make specific group comparisons. The statistical software SigmaStat32 was used. The statistical significance criterion was $p<0.05$.

\section{RESULTS}

\section{Conditioning with Neurotoxins}

The defensive reflex conditioning on shell tapping was achieved within 6 days with the use of 300-350 repetitions of a combination of shell tapping (conditioned stimulus) and air blowing into pneumostome (unconditioned stimulus) in the case of the second protocol (Figures 1A,B, SS $+\mathrm{T}$ ) or within 3 days with the use of 150 combinations in the case of first protocol (Figure 2B, SS $+\mathrm{T}$ ). In both cases the share of positive responses to a conditioned stimulus during training reached $100 \%$. The results of behavioral experiments showed a reliable maintenance of the conditioned defensive reflex for 40 days after training. Snails from the active control group received an identical amount of the conditioned and unconditioned stimuli, but in an unpaired combination. In this case the share of positive responses to a conditioned stimulus in this experimental series during training reached 25-30\% (Figure 1B, SS + AC), which proved to be less $(p<0.01)$ than that in the experimental group (up to $100 \%)$. It was found that the conditioned defensive reflex wasn't induced in snails (with the first protocol) which were trained the day after the second injection of the "neurotoxic" serotonin analog, 5,6DHT, (Figure 2B, DHT1 + T). At the same time, in the animals this reflex started to form 1 week after the second injection of the neurotoxin, there was an increased reaction to the conditioned stimulus at the end of the training session and conditioned reflex was successfully elaborated a (Figure 2B, DHT2 + T). From Figure $2 \mathrm{~A}$ we see that snails begin to learn on 13 th day after the second injection of 5,6-DHT. These results probably indicate that 2 weeks after the application of 5,6-DHT the 5-HT system, required for defensive reflex conditioning, begins to recover. It should be noted that the curves for training in naive snails and the snails injected with saline solution did not reliably differ.

\section{Conditioning with Serotonin and 5-hydroxytryptophan}

In the following series of experiments (Figure 3A) the defensive reflex conditioning on shell tapping in snails (the second protocol) was progressed more slowly, so that complete learning was achieved as a result of 350 stimuli combinations (Figure 3B, $\mathrm{SS}+\mathrm{T})$. The daily injection of 5-HTP before each training session did not reliably accelerate the defensive reflex conditioning during most of the training (Figure 3B, 5-HTP + T). However, after injections of 5-HTP the snails learned faster. Injection of 5,7-DHT inhibited learning (Figure 3B, DHT + SS + T). From Figure $3 \mathrm{~A}$ we see that even on the 16-th day after injection of 5,7-DHT snails didn't start to learn. However, daily injection of 5-HTP after the injection of 5,7-DHT restored the snail's ability to learn (Figure 3B, DHT +5 -HTP + T). A daily injection of 5HT before the training session accelerated the conditioned reflex elaboration (Figure 1B, 5-HT $+\mathrm{T}$ ). 
A
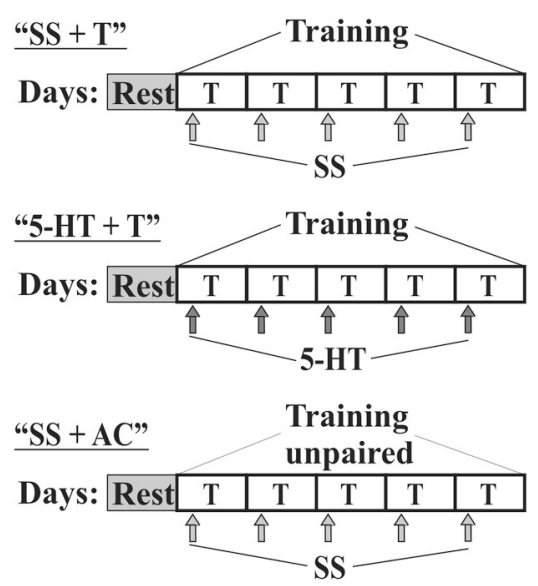

B

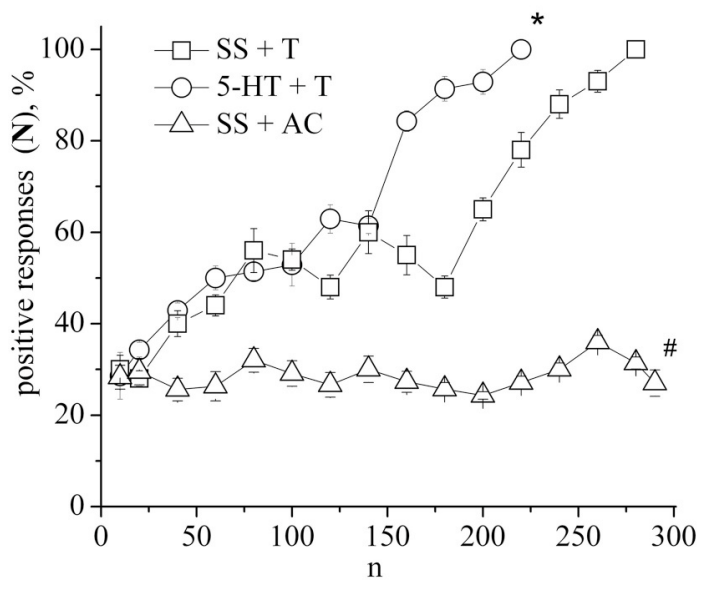

FIGURE 1 | (A) Protocol of experiments. (B) Dynamics of defensive reflex conditioning on tapping on shell in snails according to the second protocol after daily injections of serotonin $(5-H T+T)$ and saline solution $(S S+T)$ before each training session. $\mathrm{N}$, number of pairings of conditioned and unconditioned stimuli; positive responses $(\mathrm{N}), \%$, part of positive responses to conditioned stimulus, as a percentage; $5-\mathrm{HT}+\mathrm{T}$, defensive reflex conditioning during daily injections of serotonin; SS $+\mathrm{T}$, defensive reflex conditioning during daily injections of saline solution; SS + AC, active control-snails received unpaired unconditioned and conditioned stimuli. Vertical axis shows quantity of positive responses of pneumostome (its closure in response to conditioned stimulus), in \%; horizontal axis shows numbers of pairs of unconditioned and conditioned stimuli (n). One-Way ANOVA followed by Tukey post-hoc test was performed for each time point. Asterisk $\left(^{*}\right)$ indicates significant difference in the post-hoc test between $(\mathrm{SS}+\mathrm{T}) /(5-\mathrm{HT}+\mathrm{T})$ on 220 pairs. Sharp (\#) indicate significant differences $(\mathrm{SS}+\mathrm{T}, 5-\mathrm{HT}+\mathrm{T})$ vs. $(\mathrm{SS}+\mathrm{AC})$ after the first 30th pairs. ( $p<0.05$, the Tukey post-hoc test and independent $t$-test).

\section{Electrophysiological Data}

Example traces of recorded electrical characteristics of premotor interneurons in naive and trained snails are given in Figures 4A,B. Measurements of electrical characteristics (Figure 4C) showed that the initial membrane resting potential in withdrawal interneurons in the naive snails was $-60.9 \pm 0.3 \mathrm{mV}(n=92)$, the threshold potential was $19.9 \pm$ $0.4 \mathrm{mV}(n=76)$ (Figures $\mathbf{5 A}, \mathbf{B}$-Control). After associative learning $(n=74)$ a reliable decrease in the membrane resting and threshold potentials by $4 \mathrm{mV}$ was observed in the studied interneurons (Figures $\mathbf{5 A}, \mathbf{B}-\mathrm{SS}+\mathrm{T}$ ). It was found that these changes in the observed electrical characteristics were retained for 1 month. The duration this change in electrical characteristics of premotor interneurons $(n=19)$ has been shown by us earlier (Gainutdinova et al., 2003).

After injection of 5,6/5,7-DHT the depolarization of the membrane in premotor interneurons was observed during recording, both the next day and a week after the injection of 5,6DHT. The resting membrane potential decreased from $-60.3 \pm$ $0.3 \mathrm{mV}$ in SS-injected snails $(n=37)$ to $-57.2 \pm 0.3 \mathrm{mV}$ in 5,6-DHT-injected snails $(n=41)$, the threshold potential decreased from $19.9 \pm 0.3 \mathrm{mV}(n=22)$ to $17.3 \pm 0.3 \mathrm{mV}$ $(n=33)$ accordingly (Figures $5 \mathbf{A}, \mathbf{B}-\mathrm{DHT})$. In snails trained after the second injection of 5,6-DHT no further decrease of the resting membrane and threshold potentials was observed in comparison with the snails injected with 5,6-DHT without training (Figures 5A,B-DHT1 + T, DHT2 + T).

Next, we analyzed the changes in the membrane and threshold potentials of premotor interneurons of snails having received only the injection of 5-HT, and snails, injected with 5-HT before the associative learning. The membrane potential decreased from $-60.3 \pm 0.6 \mathrm{mV}(n=12)$ to $-55.7 \pm 0.4 \mathrm{mV}(n=13)$ in snails which received 5-HT only and to $-55.0 \pm 0.4 \mathrm{mV}(n=$ 12) in snails injected with 5 -HT before the elaboration of the defensive reflex. In this case in interneurons the value of the threshold potential significantly decreased from $20.0 \pm 0.5 \mathrm{mV}$ $(n=12)$ to $15.9 \pm 0.3 \mathrm{mV}(n=10)$ and to $15.3 \pm 0.3 \mathrm{mV}$ $(n=8)$, respectively (Figure 6, 5-HT, $5-\mathrm{HT}+\mathrm{T})$.

\section{DISCUSSION}

It is well known that learning on the basis of the defensive reflexes of molluscs is mediated by 5 -HT (Kandel and Schwartz, 1982; Balaban et al., 2001; Burrell and Sahley, 2005; Gillette, 2006; Il-Han et al., 2010; Hart et al., 2011). The investigations of mechanisms of learning and memory have resulted in new experimental approaches for studying the neurotransmitter and modulator effects of 5-HT, and for studying the mechanisms of participation of corresponding systems in the phenomena of behavioral plasticity (Glanzman et al., 1989; Balaban, 2002, 2008; Barbas et al., 2003; Crow, 2004; Burrell and Sahley, 2005; D'iakonova, 2007; Il-Han et al., 2010; Hart et al., 2011). It is well known that 5-HT induces presynaptic facilitation (Byrne and Kandel, 1996; Lin et al., 2010), it has also been shown that 5-HT can perform integrative functions through its release in the extracellular medium (Sakharov, 1990; Zakharov et al., 1995; Marinesco et al., 2004). These results served as a basis for using 5-HT application to the washing solution as an analog of reinforce stimulus during the formation of cell analogs of learning (Mauelshagen et al., 1996; Liao et al., 1999; Hawkins et al., 2006; Lin et al., 2010; Hu et al., 2011).

\section{Effects of Neurotoxins Connected with Depletion of Serotonin}

Our work is devoted to the investigation of mechanisms of associative learning on the basis of the defensive reflex 


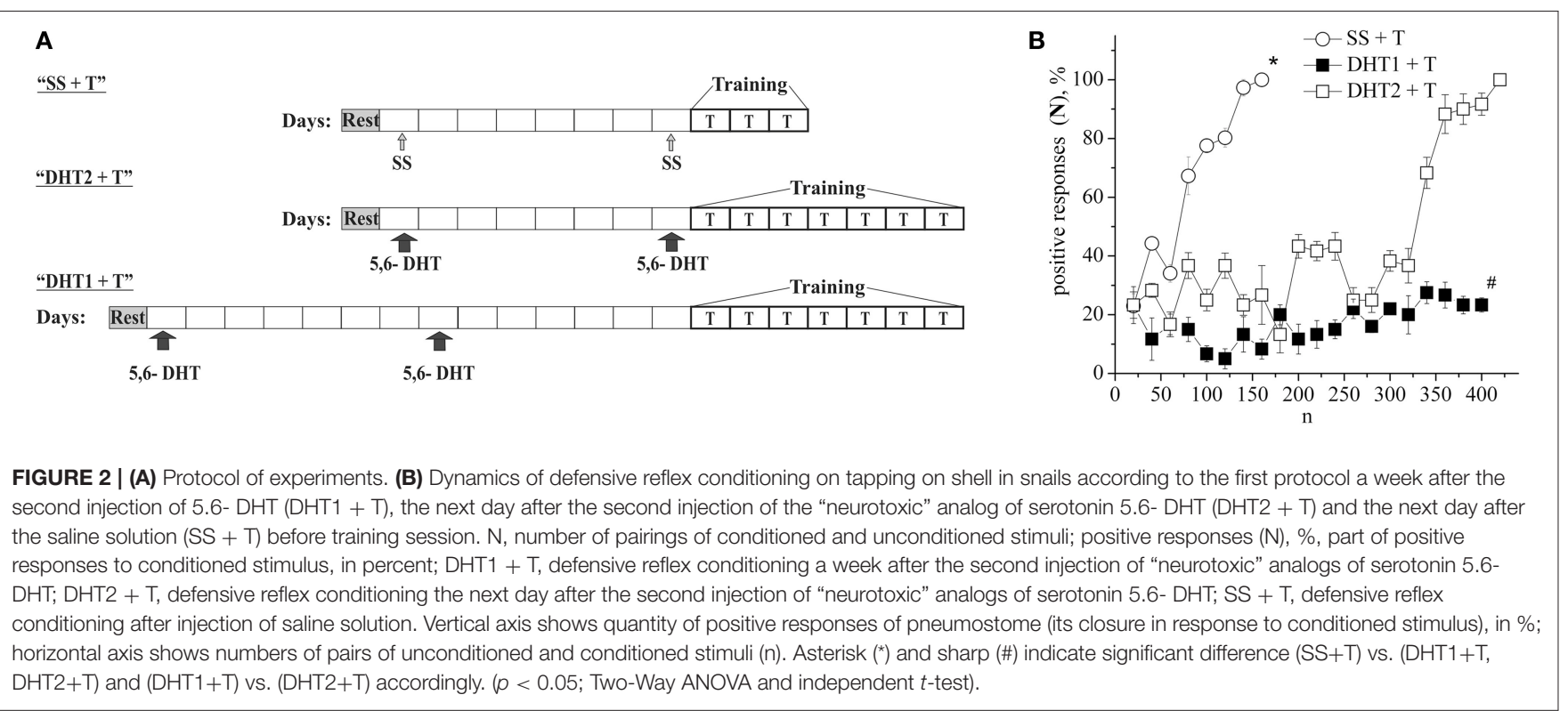

of a terrestrial snail. For the analysis of the role of 5HT, its temporary deficit using the "neurotoxic" analogs $5,6 / 5,7-\mathrm{DHT}$ was created. The predecessor for the synthesis of serotonin 5-HTP as well as the injection of 5-HT in the hemolymph of the snail Helix pomatia were also used. Our results as in the work of Balaban et al. (1987) show that after depletion of 5-HT the conditioned reflex is not produced. These results correlate with the data of Glanzman et al. (1989) which show the inhibition of the heterosynaptic facilitation in Aplysia by the neurotoxin 5,7-DHT. Data from the literature (Pivovarov and Nistratova, 2003; Abramova et al., 2005) and our results show that premotor interneurons respond to 5-HT, i.e., 5-HT may modulate the behavioral effects. Direct evidence of the possibility of electrophysiological modulatory effects of the serotonergic neuron $\mathrm{Pd} 4$ on the premotor interneuron LPa3 was found by Balaban et al. (2001).

One of the possible reasons for such effects is a depletion of $5-\mathrm{HT}$ in the nervous system of mollusks by neurotoxins (Gadotti et al., 1986; Glanzman and Krasne, 1986; Jahan-Parwar et al., 1987; Vehosvzky et al., 1989; Kemenes et al., 1990). It was shown early that the "neurotoxic" analogs 5,7-DHT significantly reduced the immunofluorescence staining of 5-HT in the nervous system of crayfish (Glanzman and Krasne, 1986), analysis using HPLC also shows a decrease in the level of 5HT in the nervous system of Aplysia after exposure to this neurotoxin (Glanzman et al., 1989). The results of ultrastructural and biochemical studies showed significant depletion of 5HT by 5,6-DHT in the first week, and after 21 days the levels of 5-HT returned to normal level (Hernádi et al., 1992; Kemenes, 1997). Our results showed that the snails start to learn on the 13th day after the injection of 5,6-DHT, but after injection of 5,7-DHT snails hadn't even started to learn on the 16-th day.

\section{Excitability of Premotor Interneurons and Learning}

Earlier we found that the defensive reflex conditioning in snails is accompanied by a depolarization shift of the membrane potential and a decrease of the threshold potential (Gainutdinov et al., 1998). In recent years there have been a sufficient number of experimental results that demonstrate the membrane correlates of learning (Gillette et al., 1982; Alkon, 1984; Frysztak and Crow, 1997; Cleary et al., 1998; Gainutdinova et al., 2003; Disterhoft and Oh, 2006; Kemenes et al., 2006; Nikitin et al., 2006, 2013; Mozzachiodi et al., 2008; Jing et al., 2009; Debanne and Poo, 2010; Gainutdinov et al., 2011; Sakharov, 2012; Cavallo et al., $2014 a, b)$. These experiments were done on preparations from trained animals as well as within the cell analogs of learning.

A number of questions arise during the analysis of the effects of 5-HT. It is known that one of the main functions of 5HT both in vertebrates and invertebrates is to facilitate the motor output. For example, the facilitation action on reflex activity and on central pattern generators (Gillette, 2006). The increase in excitability of neurons under the action of 5-HT has been noted by a number of authors (Frysztak and Crow, 1997; Liao et al., 1999; Balaban et al., 2001; Pivovarov and Nistratova, 2003; Abramova et al., 2005; Dumitriu et al., 2006; Hawkins et al., 2006). Jin and co-authors have shown that 5-HT increases the peak amplitude of the complex excitatory postsynaptic potential induced by light, and also increases the internal excitability and the spike activity of type $\mathrm{Ie}(\mathrm{A})$ interneurons of the mollusk Hermissenda (Jin et al., 2009). In contrast 5HT reduces the spike activity and internal excitability of type $\mathrm{Ie}(\mathrm{B})$ interneurons. We found two effects in our experiments: the depolarization shift of membrane potential and decrease in the threshold potential of premotor interneurons after training and after the injection of the 5-HT. There is an absence of a summing effect of these two factors. The depolarization shift 


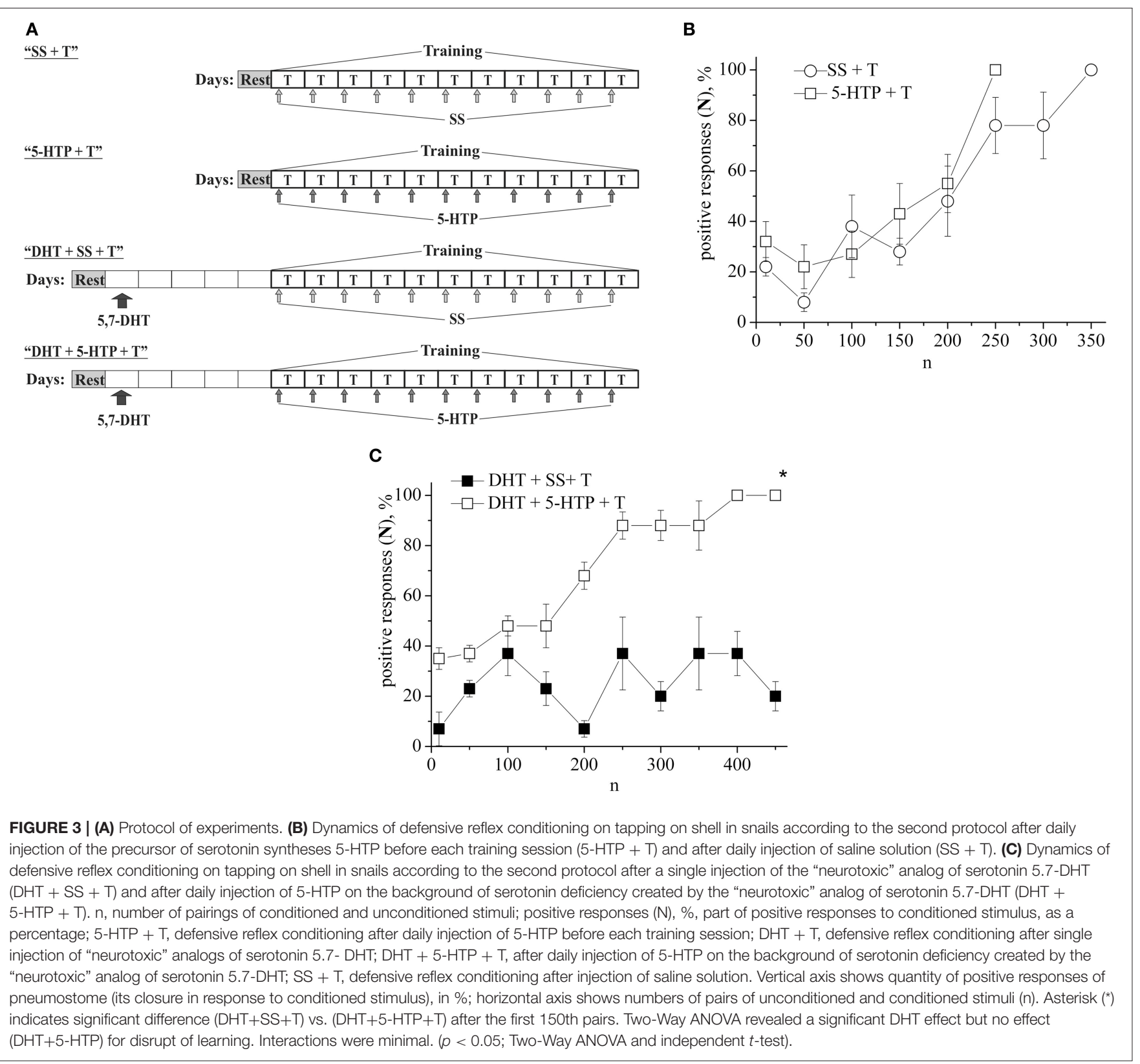

of membrane potential and decrease in threshold potential of premotor interneurons in response to injection of 5-HT and its "neurotoxic" analogs to intact snails is a possible consequence of coupling of these substances (5-HT and neurotoxins) with 5-HT receptors.

\section{Serotonin Receptors in Premotor Interneurons}

In our experiments we have shown that injections of the neurotoxins 5,6/5,7-DHT is accompanied by the depolarization of premotor interneurons and a decrease in their threshold potential, as with injections of 5-HT. The question arises, are the depolarization shift of membrane potential and decrease in threshold potential of premotor interneurons after injection of
5-HT and its neurotoxic analogs the result of their interaction with 5-HT- receptors due to the structural similarity between 5HT and its neurotoxic analogs? These common effects suggest that they are related to the effects of 5-HT on receptors located on the membrane of premotor interneurons and possibly on the intermediate neurons that are presynaptic to premotor interneurons. Pivovarov and Nistratova (2003) analyzed the possible presence of 5-HT receptors on the soma of snail's premotor interneurons. 5-HT, applied locally to the soma, reversibly decreased the input current caused by acetylcholine (local ionophoretical application). They demonstrated that only NAN-190 (a 5-HT 1 A-receptor antagonist) and methiothepin (a $5-\mathrm{HT}_{1 \mathrm{E}}$ receptor antagonist) inhibited the development of the 5HT effect. The results show the presence of 5 -HT receptors but 


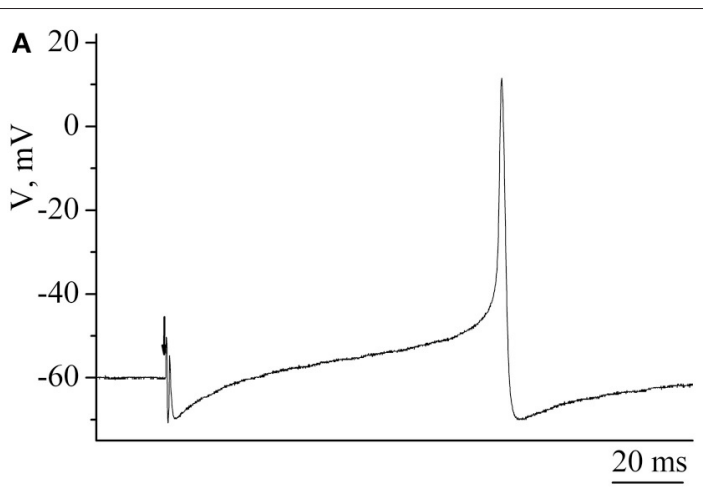

B

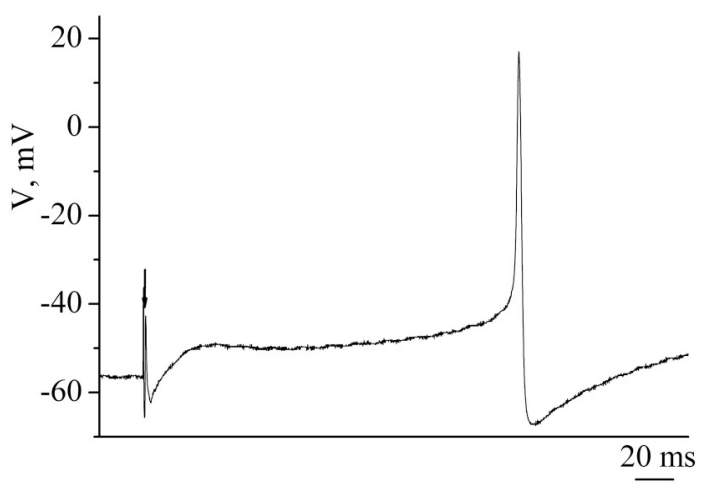

C

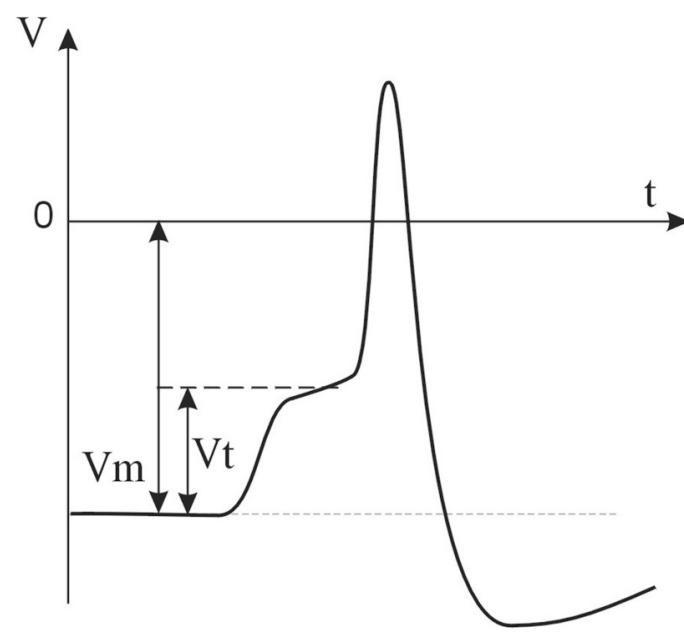

FIGURE 4 | The action potentials of premotor interneurons of intact (A) and learned (B) snails. (C) Schematic figure of action potential of premotor interneuron and its basic electric characteristics. Vertical axis shows value of potential, in $\mathrm{mV}$; horizontal axis shows time, in ms.

only of the first type on the soma of Helix premotor interneurons (Pivovarov and Nistratova, 2003; Abramova et al., 2005).

It is known that the 5-HT1A receptor is among the most abundant and widely distributed 5-HT receptors in the brain, but is also expressed on 5-HT neurons as an autoreceptor where it plays a critical role in regulating the activity of the entire 5-HT system and over-expression of the 5-HT1A autoreceptor has been implicated in reducing 5-HT neurotransmission
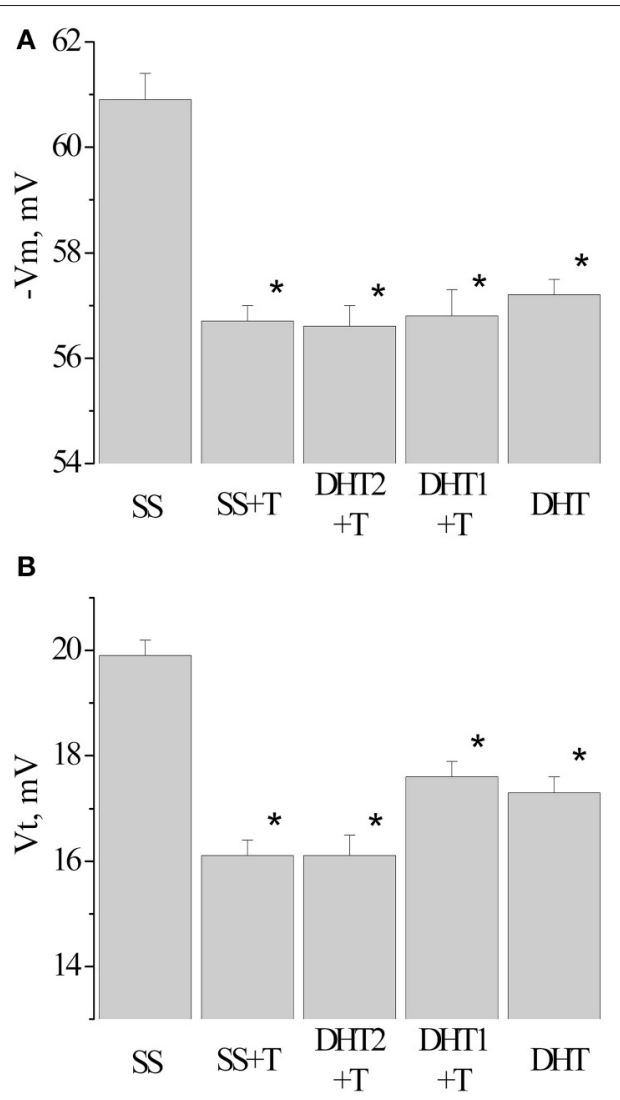

FIGURE 5 | Value of resting membrane potential-(A) and threshold potential-(B) of premotor interneurons $\mathrm{LPa} 3$ and RPa3 in snails in various conditions. SS, naïve snails; $\mathrm{DHT} 1+\mathrm{T}$, defensive reflex conditioning a week after the second injection of the "neurotoxic" analog of serotonin 5.6$\mathrm{DHT}$; DHT2 $+\mathrm{T}$, defensive reflex conditioning the next day after the second injection of the "neurotoxic" analog of serotonin 5.6- DHT; SS + T, defensive reflex conditioning after injection of saline solution; $\mathrm{DHT}$, snails injected by the "neurotoxic" analog of serotonin 5.6- DHT. *The reliable difference $(p<0.001)$ against active control group (injection of saline solution). Vertical axis shows the value of potential, in mV. ANOVA revealed no T/DHT/5-HT interactions. ${ }^{*} p<0.05$; Two-Way ANOVA and independent $t$-test.

(Albert et al., 2011). Our results showed that 5-HT and its neurotoxin produced similar effects. It is possible to consider the results obtained with 5-HT1A autoreceptors. It has been shown that most if not all 5-HT1A autoreceptors on the plasma membrane of soma-dendrites from nucleus raphe dorsalis are located extrasynaptically (Riad et al., 2004). Therefore, 5-HT and its neurotoxin may bound with these autoreceptors and decrease the effect of 5-HT. However, the question remains whether the 5-HT1A receptors in the premotor interneurons are autoreceptors?

It has been shown that the broadening of the action potential of Aplysia sensory neurons in response to 5-HT application is mediated by 5-HT receptors of the first type, blocked by methiothepin (Dumitriu et al., 2006). K. Lukowiak et al studied the role of the 5-HT- system in the responses of the mollusk Lymnaea to the danger stimulus. Using mianserin, a 5-HT receptor antagonist they found the disruption of two types of 


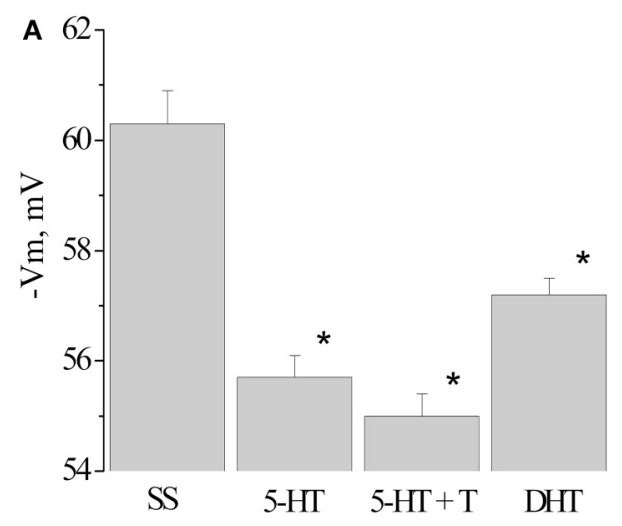

B

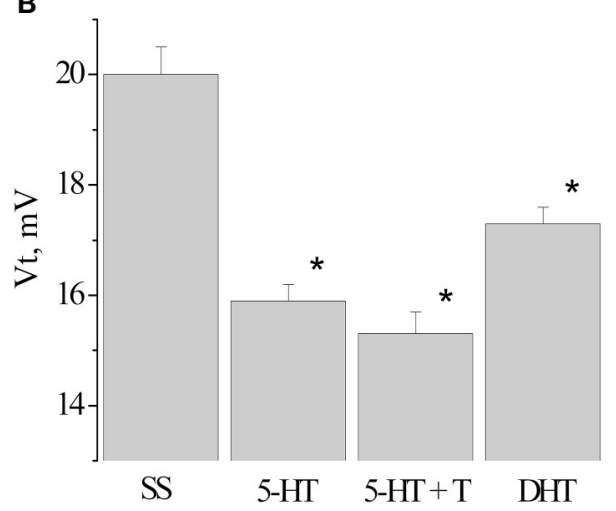

FIGURE 6 | Value of resting membrane potential-(A) and threshold potential $-(\mathrm{B})$ of premotor interneurons $\mathrm{LPa} 3$ and $\mathrm{RPa} 3$ in snails learned in various conditions. SS, naïve snails; $5-\mathrm{HT}$, snails injected by serotonin; $5-\mathrm{HT}+\mathrm{T}$, defensive reflex conditioning after daily injection of serotonin; DHT, snails injected by the "neurotoxic" analog of serotonin 5.6DHT. *The reliable difference $(p<0.001)$ against active control group (injection of saline solution). Vertical axis shows the value of potential, in $\mathrm{mV}$. ANOVA revealed no T/DHT/5-HT interactions. ${ }^{*} p<0.05$; Two-Way ANOVA and independent $t$-test.

defensive behavior (increase in the time of exit of freshwater snail from their shell and the shadow reflex), caused by an extract of crab tissue (Il-Han et al., 2010). Methysergide, another 5-HT receptor antagonist had the same effect, blocking the formation of long-term memory after training with an extract of crab tissue. However, importantly, mianserin didn't affect formation of long-term memory after training in water without an extract of crab tissue. These data suggest that the 5-HT- system is activated only with danger detection. These results show the possibility of an extracellular action of 5-HT. The differences in the responses to 5-HT led to the opinion that there are different subtypes of 5-HT receptors in the nervous system of Aplysia (Barbas et al., 2003). The possibility of participation of different types of 5-HT receptors in different signaling pathways has also been demonstrated in the work of Kiss et al. (2003). Since potentiation of S-cells in the leech was blocked by the 5-HT receptor antagonist methylsergide, it was concluded that this metabotropic receptor is involved in the regulation of excitability of S-cells (Burrell and Sahley, 2005). Other researchers have cloned a 5-HT receptor called 5-HT(apAC1), which stimulates the production of cAMP, the inhibition of which blocks synaptic facilitation of the sensorimotor synapse of Aplysia (Lee et al., 2009). A 5-HT receptor, which regulates protein kinase C PKC has also been found, called Apl II (Nagakura et al., 2010).

\section{Effects of Serotonin and 5-hydroxytryptophan Injections on Learning}

It is known that 5 -HT is an important mediator of defensive behavior in molluscs (Whitaker-Azmitia, 1999; Gillette, 2006; D'iakonova, 2007; Hernadi et al., 2008; Lee et al., 2009). It has been shown that the 5-HT transmission from modulatory neurons to premotor interneurons includes the release of 5HT from modulatory neurons into the extracellular medium (Zakharov et al., 1995; Balaban et al., 2001). We found that daily injection of 5-HT accelerated the defensive reflex conditioning in snails. This result is similar to those found by Lee et al. (2008). They found that one pulse of 5HT produces a transient facilitation mediated by the cAMPdependent protein kinase leading to covalent modifications in the sensory neurons which results in an enhancement of transmitter release and a strengthening of synaptic connections lasting minutes. By contrast, repeated pulses of 5-HT induce a transcription- and translation-dependent long-term facilitation lasting more than $24 \mathrm{~h}$ and trigger the activation of a family of transcription factors in the presynaptic sensory neurons including ApCREB1, ApCREB2, and ApC/EBP. Other researchers have also shown that 5-HT-induced long-term facilitation of the Aplysia sensorimotor synapse depends on enhanced gene expression and protein synthesis (Villareal et al., 2007; Hart et al., 2011). There is evidence that one of these proteins could be synapsin (Fioravante et al., 2007; Hart et al., 2011).

5-HTP didn't reliably accelerate the defensive reflex conditioning during training, however, after injection of 5-HTP learning in general was achieved faster. Our results demonstrate that daily injection of 5-HTP before a training session in snails with a 5-HT deficiency, created by the "neurotoxic" analog of serotonin 5,7-DHT, restored the ability of snails to learn. The explanation for this fact can be found in the data of Fickbohm et al. (2005). Using high performance liquid chromatography and immunochemistry they showed a significant increase in 5-HTP content for over $20 \mathrm{~h}$ in the brain of a mollusk Tritonia after $30 \mathrm{~min}$ standing in a solution of $2 \mathrm{mM} \mathrm{5-HTP}$ and they also showed the increase of 5-HT in specific areas of the brain (Fickbohm et al., 2005). The difference in our experiments is that we not only injected snails with 5-HT and 5-HTP but also elaborated a conditioned reflex, i.e., had to deal with the simultaneous action of two factors. So the question arose by what mechanisms does 5-HT accelerate learning? It is known that learning is the result of changes in presynaptic processes, such as direct modulation of the release of neurotransmitters and postsynaptic processes, such as the properties of receptors (Kandel, 1976, 2001; Hawkins et al., 2006; Balaban, 2008; Mozzachiodi and Byrne, 2010; Vavoulis et al., 2010; Balaban et al., 2014). At 
the same time the effect of recovery in the ability to learn caused by injections of 5-HTP on the background of deficiency of 5-HT created by 5,7-DHT, demonstrates a partial maintenance of the functioning of the 5-HT synapses.

\section{CONCLUSION}

In conclusion, we have shown that a daily injection of 5HT before a training session accelerated learning, and daily injection of 5-HTP before a training session in snails with a 5-HT deficiency (caused by the "neurotoxic" analogs of serotonin 5,7-DHT), restored the ability of snails to learn. The results suggest that during learning $5-\mathrm{HT}$ is released into the extracellular medium, which interacts with receptors located

\section{REFERENCES}

Abramova, M. S., Nistratova, V. L., Moskvitin, A. A., and Pivovarov, A. S. (2005). Methiothepin-sensitive serotonin receptors are involved in the postsynaptic mechanism of sensitization of the defensive response of the common snail. Zh. Vyssh. Nerv. Deiat. Im. I. P. Pavlova 55, 385-392. doi: 10.1007/s11055-0060062-4

Albert, P. R., Francois, B. L., and Millar, A. M. (2011). Transcriptional dysregulation of 5-HT1A autoreceptors in mental illness. Mol. Brain 4:21. doi: 10.1186/1756-6606-4-21

Alkon, D. L. (1984). Changes of membrane currents during learning. J. Exp. Biol. 112, 95-112.

Balaban, P. M. (1993). Behavioral neurobiology of learning in terrestrial snails. Prog. Neurobiol. 41, 1-19. doi: 10.1016/0301-0082(93)90038-T

Balaban, P. M. (2002). Cellular mechanisms of behavioral plasticity in terrestrial snail. Neurosci. Biobehav. Rev. 26, 597-630. doi: 10.1016/S0149-7634(02) 00022-2

Balaban, P. M. (2008). Cellular mechanisms of behavioral plasticity in simple nervous system. Neurosci. Behav. Physiol. 38, 453-462. doi: 10.1007/s11055008-9002-9

Balaban, P. M., Roshchin, M. V., Timoshenko, A. K., Gainutdinov, K. L., Bogodvid, T. K., Muranova, L. N., et al. (2014). Nitric oxide is necessary for labilization of a consolidated context memory during reconsolidation in terrestrial snails. Eur. J. Neurosci. 6, 2963-2970. doi: 10.1111/ejn. 12642

Balaban, P. M., Vehosvzky, A., Maksimova, O. A., and Zakharov, I. S. (1987). Effect of 5.7-dihydroxytryptamine on the food-aversive conditioning in the snail Helix lucorum L. Brain Res. 404, 201-210. doi: 10.1016/0006-8993(87)91371-0

Balaban, P. İ., Bravarenko, N. I., Maksimova, O. A., Nikitin, E., Ierusalimsky, V. N., and Zakharov, I. S. (2001). A single serotoninergic modulatory cell can mediate reinforcement in the withdrawal network of the terrestrial snail. Neurobiol. Learn. Mem. 75, 30-50. doi: 10.1006/nlme.1999.3953

Balaban, P. V., and Bravarenko, N. I. (1993). Long-term sensitization and environmental conditioning in terrestrial snails. Exp. Brain Res. 96, 487-493. doi: 10.1007/BF00234116

Barbas, D., DesGroseillers, L., Castellucci, V. F., Carew, T. J., and Marinesco, S. (2003). Multiple serotonergic mechanisms contributing to sensitization in evidence of diverse serotonin receptor subtypes Aplysia. Learn. Mem. 10, 373-386. doi: 10.1101/lm.66103

Burrell, B. D., and Sahley, C. L. (1999). Serotonin depletion does not prevent intrinsic sensitization in the leech. Learn. Mem. 6, 509-520. doi: 10.1101/lm.6.5.509

Burrell, B. D., and Sahley, C. L. (2005). Serotonin mediates learninginduced potentiation of excitability. J. Neurophysiol. 94, 4002-4010. doi: 10.1152/jn.00432.2005

Byrne, J. H., and Kandel, E. R. (1996). Presynaptic facilitation revisited: state and time dependence. J. Neurosci. 16, 5988-5998. on the membrane of premotor interneurons and possibly on the intermediate neurons that are presynaptic to premotor interneurons. Learning is also accompanied by a decrease in membrane and threshold potentials of premotor interneurons.

\section{ACKNOWLEDGMENTS}

This work was funded by the subsidy of the Russian Government to support the Program of Competitive Growth of Kazan Federal University among World's Leading Academic Centers (agreement No. 02.A03.21.0002), by Russian Foundation for Basic Research (grant No. 15-04-05487) and by Russian Scientific Foundation (grant No. 14-25-00072, in part of experiments of neurotoxins effect on learning).

Cavallo, J. S., Hamilton, B. N., and Farley, J. (2014a). Behavioral and neural bases of extinction learning in Hermissenda. Front. Behav. Neurosci. 8:277. doi: 10.3389/fnbeh.2014.00277

Cavallo, J. S., Hamilton, B. N., and Farley, J. (2014b). In vitro extinction learning in Hermissenda: involvement of conditioned inhibition molecules. Front. Behav. Neurosci. 8:354. doi: 10.3389/fnbeh.2014.00354

Cleary, L. J., Lee, W. L., and Byrne, J. H. (1998). Cellular correlates of long-term sensitization in Aplysia. J. Neurosci. 18, 5988-5998.

Crow, T. (2004). Pavlovian conditioning of Hermissenda: current cellular, molecular, and circuit perspectives. Learn. Mem. 11, 229-238. doi: 10.1101/lm.70704

Debanne, D., and Poo, M.-M. (2010). Spike-timing dependent plasticity beyond synapse - pre- and post-synaptic plasticity of intrinsic neuronal excitability. Front. Synap. Neurosci. 2:21. doi: 10.3389/fnsyn.2010.00021

Disterhoft, J. F., and Oh, M. M. (2006). Learning, aging and intrinsic neuronal plasticity. Trends Neurosci. 10, 587-599. doi: 10.1016/j.tins.2006.08.005

Dumitriu, B., Cohen, J. E., Wan, Q., Negroiu, A. M., and Abrams, T. W. (2006). Serotonin receptor antagonists discriminate between PKA- and PKC-mediated plasticity in Aplysia sensory neurons. J. Neurophysiol. 95, 2713-2720. doi: 10.1152/jn.00642.2005

D'iakonova, V. E. (2007). Behavioral functions of serotonin and octopamin: some paradoxes of comparative physiology. Usp. Physiol. Nauk 38, 3-20.

Fickbohm, D. J., Spitzer, N., and Katz, P. S. (2005). Pharmacological manipulation of serotonin levels in the nervous system of the opisthobranch mollusc Tritonia diomedea. Biol. Bull. 209, 67-74. doi: 10.2307/3593142

Fioravante, D., Liu, R.-Y., Netek, A. K., Cleary, L. J., and Byrne, J. H. (2007). Synapsin regulates basal synaptic strength, synaptic depression, and serotonininduced facilitation of sensorimotor synapses in Aplysia. J. Neurophysiol. 98, 3568-3580. doi: 10.1152/jn.00604.2007

Frysztak, R. D., and Crow, T. (1997). Synaptic enhancement and enhanced excitability in presynaptic and postsynaptic neurons in the conditioned stimulus pathway of Hermissenda. J. Neurosci. 17, 4426-4433.

Gadotti, D., Bauce, L. G., Lukowiak, K., and Bulloch, A. G. M. (1986). Transient depletion of serotonin in the nervous system of Helisoma. J. Neurobiol. 17, 431-447. doi: 10.1002/neu.480170507

Gainutdinov, K. L., Andrianov, V. V., and Gainutdinova, T. K. (1999). The action of the neurotoxins 5,6-dihydroxytryptamine and p-chlorphenylalanine on the electrical activity parameters of the command neurons during long-term sensitization and learning in the snail. Zh. Vyssh. Nerv. Deiat. Im. I. P. Pavlova $49,48-58$.

Gainutdinov, K. L., Andrianov, V. V., and Gainutdinova, T. K. (2011). Changes of the neuronal membrane excitability as cellular mechanisms of learning and memory. Usp. Physiol. Nauk 42, 33-52.

Gainutdinov, K. L., Chekmarev, L. J, and Gainutdinova, T. H. (1998). Excitability increase in withdrawal interneurons after conditioning in snail. Neuroreport 9, 517-520. doi: 10.1097/00001756-19980216000026 
Gainutdinova, T. K., Andrianov, V. V., Gainutdinov, K. L., Mukhamedshina, D. I., and Tagirova, R. R. (2003). Duration in electrical characteristics of command neurons after defensive conditioning in snail. Zh. Vyssh. Nerv. Deiat. Im. I. P. Pavlova 53, 379-382.

Gillette, R. (2006). Evolution and function in serotonergic systems. Integr. Comp. Biol. 46, 838-846. doi: 10.1093/icb/icl024

Gillette, R., Gillette, M. U., and Davis, W. J. (1982). Substrates of command ability in a buccal neuron of Pleurobranchaea. I. Mechanisms of action potential broadening. J. Comp. Physiol. 146, 449-459. doi: 10.1007/BF00609441

Glanzman, D. L., and Krasne, F. B. (1986). 5,7-Dihydroxytryptamine lesions of crayfish serotonin-containing neurons: effect on the lateral giant escape reaction. J. Neurosci. 6, 1560-1569.

Glanzman, D. L., Mackey, S. L., Hawkins, R. D., Dyke, A. M., Lloyd, P. E., and Kandel, E. R. (1989). Depletion of serotonin in the nervous system of Aplysia reduces the behavioral enhancement of gill withdrawal as well as the heterosynaptic facilitation produced by tail shock. J. Neurosci. 12, 4200-4213.

Hart, A. K., Fioravante, D., Liu, R.-Y., Phares, G. A., Cleary, L. J., and Byrne, J. H. (2011). Serotonin-mediated synapsin expression is necessary for long-term facilitation of the Aplysia sensorimotor synapse. J. Neurosci. 31, 18401-18411. doi: 10.1523/JNEUROSCI.2816-11.2011

Hawkins, R. D., Kandel, E. R., and Bailey, C. H. (2006). Molecular mechanisms of memory storage in Aplysia. Biol. Bull. 210, 174-191. doi: 10.2307/4134556

Hernádi, L., Hiripi, L., Vehovszky, A., Kemenes, G., and Rózsa, K. (1992). Ultrastructural, biochemical and electrophysiological changes induced by 5,6dihydroxytryptamine in the CNS of the snail Helix pomatia L. Brain Res. 578, 221-234. doi: 10.1016/0006-8993(92)90251-4

Hernadi, L., Karpati, L., Gyori, J., Vehovszky, A., and Hiripi, L. (2008). Humoral serotonin and dopamine modulate the feeding in the snail, Helix pomatia L. Acta Biol. Hung. 59, 39-46. doi: 10.1556/ABiol.59.2008.Suppl.6

Hu, J.-Y., Baussi, O., Levine, A., Chen, Y., and Schacher, S. (2011). Persistent long-term synaptic plasticity requires activation of a new signaling pathway by additional stimuli. J. Neurosci. 31, 8841-8850. doi: 10.1523/JNEUROSCI.135811.2011

Il-Han, J., Janes, T., and Lukowiak, K. (2010). The role of serotonin in the enhancement of long-term memory resulting from predator detection in Lymnaea. J. Exp. Biol. 213, 3603-3614. doi: 10.1242/jeb.048256

Jahan-Parwar, B. S., Rozsa, K., Salanki, J., Evans, M. L., and Carpenter, D. (1987). In vivo labeling of serotonin-containing neurons by 5,7-dihydroxytryptamine in Aplysia. Brain Res. 426, 173-178. doi: 10.1016/0006-8993(87)90438-0

Jin, N. G., Tian, L.-M., and Crow, T. (2009). 5-HT and GABA modulate intrinsic excitability of type I interneurons in Hermissenda. J. Neurophysiol. 102, 2825-2833. doi: 10.1152/jn.00477.2009

Jing, J., Gillette, R., and Weiss, K. R. (2009). Evolving concepts of arousal: insights from simple model systems. Rev. Neurosci. 20, 405-427. doi: 10.1515/revneuro.2009.20.5-6.405

Kandel, E. R. (1976). Cellular Basis of Behavior. San Francisco, CA: W.N. Freeman and Co.

Kandel, E. R. (2001). The molecular biology of memory storage: a dialogue between genes and synapses. Science 294, 1030-1038. doi: 10.1126/science.1067020

Kandel, E. R., and Schwartz, J. H. (1982). Molecular biology of learning: modulation of transmitter release. Science 218, 433-442. doi: $10.1126 /$ science.6289442

Kemenes, G. (1997). In vivo neuropharmacological and in vitro laser ablation techniques as tools in the analysis of neuronal circuits underling behaviour in a molluscan model system. Gen. Pharmacol. 29, 7-15. doi: 10.1016/S03063623(96)00520-4

Kemenes, G., Hiripi, L., and Benjamin, P. R. (1990). Behavioural and biochemical changes in the feeding system of Lymnaea induced by the dopamine and serotonin neurotoxins 6-hydroxdopamine and 5,6-dihydroxytryptamine. Philos. Trans. R. Soc. Lond. 329, 243-255. doi: 10.1098/rstb.1990.0168

Kemenes, I., Straub, V. A., Nikitin, E. S., Staras, K., O’Shea, M., Kemenes, G., et al. (2006). Role of delayed nonsynaptic neuronal plasticity in longterm associative memory. Curr. Biol. 16, 1269-1279. doi: 10.1016/j.cub.2006. 05.049

Kilias, R. (1985). Die Weinbergschnecke Uber Leben und Nutzung von Helix Pomatia. Wittenberg; Litherstadt: A. Ziemsen Verlag.

Kiss, T., Hiripi, L., Papp, N., and Elekes, K. (2003). Dopamine and serotonin receptors mediating contractions of the snail, Helix pomatia, salivary duct. Neuroscience 116, 775-790. doi: 10.1016/S0306-4522(02) 00754-6

Lee, Y.-S., Bailey, C. H., Kandel, E. R., and Kaang, B.-K. (2008). Transcriptional regulation of long-term memory in the marine snail Aplysia. Mol. Brain 1:3. doi: 10.1186/1756-6606-1-3

Lee, Y.-S., Choi, S.-L., Lee, S.-H., Kim, H., Park, H., Lee, N., et al. (2009). Identification of a serotonin receptor coupled to adenylyl cyclase involved in learning-related heterosynaptic facilitation in Aplysia. Proc. Nat. Acad. Sci. U.S.A. 106, 14634-14639. doi: 10.1073/pnas.0907502106

Lent, C. M., and Dickinson, M. N. (1984). Retzius cells retain functional membrane properties following "ablation" by toxin 5,6-DHT. Brain Res. 300, 167-171. doi: 10.1016/0006-8993(84)91353-2

Levenson, J., Byrne, J. H., and Eskin, A. (1999). Levels of serotonin in the hemolymph of Aplysia are modulated by light/dark cycles and sensitization training. J. Neurosci. 19, 8094-8103.

Liao, X., Brou, C. G., and Walters, E. T. (1999). Limited contributions of serotonin to long-term hyperexcitability of Aplysia sensory neurons. J. Neurophysiol. 82, 3223-3235.

Lin, A. H., Cohen, J. E., Wan, Q., Niu, K., Shrestha, P., Bernstein, S. L., et al. (2010). Serotonin stimulation of cAMP-dependent plasticity in Aplysia sensory neurons is mediated by calmodulin-sensitive adenylyl cyclase. Proc. Nat. Acad. Sci. U.S.A. 107, 15607-15612. doi: 10.1073/pnas.1004451107

Malyshev, A.,Yu., Bravarenko, N. I., Pivovarov, A. S., and Balaban, P. M. (1997). Effects of serotonin levels on postsynaptically induced potentiation of snail neuron responses. Zh. Vyssh. Nerv. Deiat. Im. I. P. Pavlova 47, 553-562.

Marinesco, S., Wickremasinghe, N., Kolkman, K. E., and Carew, T. J. (2004). Serotonergic modulation in Aplysia. II. Cellular and behavioral consequences of increased serotonergic tone. J. Neurophysiol. 92, 2487-2496. doi: 10.1152/jn.00210.2004

Mauelshagen, J., Parker, G. R., and Carew, T. J. (1996). Dynamics of induction and expression of long-term synaptic facilitation in Aplysia. J. Neurosci. 16, 7099-7108.

Mozzachiodi, R., and Byrne, J. H. (2010). More than synaptic plasticity: role of nonsynaptic plasticity in learning and memory. Trends Neurosci. 33, 17-26. doi: 10.1016/j.tins.2009.10.001

Mozzachiodi, R., Lorenzetti, F. D., Baxter, D. A., and Byrne, J. H. (2008). Changes in neuronal excitability serve as a mechanism of long-term memory for operant conditioning. Nat. Neurosci. 11, 1146-1148. doi: 10.1038/nn.2184

Nagakura, I., Dunn, T. W., Farah, C. A., Hepner, A., Li, F. F., and Sossin, W. S. (2010). Persistent sodium current is a target for cAMP-induced neuronal plasticity in a state-setting modulatory interneuron. J. Neurochem. 115, 994-1006. doi: 10.1111/j.1471-4159.2010.06986.x

Nikitin, E. S., Balaban, P. M., and Kemenes, G. (2013). Nonsynaptic plasticity underlies a compartmentalized increase in synaptic efficacy after classical conditioning. Curr. Biol. 23, 614-619. doi: 10.1016/j.cub.2013.02.048

Nikitin, E. S., Kiss, T., Staras, K., O'Shea, M., Benjamin, P. R., and Kemenes, G. (2006). Persistent sodium current is a target for cAMP-induced neuronal plasticity in a state-setting modulatory interneuron. J. Neurophysiol. 95, 453-463. doi: 10.1152/jn.00785.2005

Pivovarov, A. S., and Nistratova, V. L. (2003). Modulatory serotonin receptors on the soma of command neurons in edible snail. Bull. Exp. Biol. Med. 136, 114-116. doi: 10.1023/A:1026390117562

Riad, M., Zimmer, L., Rbah, L., Watkins, K. C., Hamon, M., and Descarries, L. (2004). Acute treatment with the antidepressant fluoxetine internalizes 5HT1A autoreceptors and reduces the in vivo binding of the PET radioligand $\left[{ }^{18} \mathrm{~F}\right] \mathrm{MPPF}$ in the nucleus raphe dorsalis of rat. J. Neurosci. 24, 5420-5426. doi: 10.1523/JNEUROSCI.0950-04.2004

Sakharov, D. A. (1990). Integrative function of serotonin in primitive Metazoa. Zurnal Obchei Biologii 51, 437-449.

Sakharov, D. A. (2012). Biological substrate for generation of behavioral acts. Zurnal Obchei Biologii 73, 324-348.

Schmalz, E. (1914). Zur Morphologie des Nervensystems von Helix pomatia. Zitschrift Wissenshaft Zoology 3, 506-568.

Shevelkin, A. V., Nikitin, V. P., Kozyrev, S. A., Samoilov, M. O., and Sherstnev, V. V. (1997). Serotonin imitates several of the neuronal effects of nociceptive sensitization in the common snail. Zh. Vyssh. Nerv. Deiat. Im. I. P. Pavlova 47, $532-542$. 
Vavoulis, D. V., Nikitin, E. S., Kemenes, I., Marra, V., Feng, J., Benjamin, P. R., et al. (2010). Balanced plasticity and stability of the electrical properties of a molluscan modulatory interneuron after classical conditioning: a computational study. Front. Behav. Neurosci. 4:19. doi: 10.3389/fnbeh.2010.00019

Vehosvzky, A., Kemenes, G., and S-Rozsa, K. (1989). Monosynaptic connections between serotonin-containing neurons labelled by 5.6-dihydroxytryptamineinduced pigmentation in the snail Helix pomatia L. Brain Res. 484, 404-407. doi: 10.1016/0006-8993(89)90390-9

Villareal, G., Li, Q., Cai, D., and Glanzman, D. L. (2007). The role of rapid, local, postsynaptic protein synthesis in learning-related synaptic facilitation in Aplysia. Curr Biol. 17, 2073-2080. doi: 10.1016/j.cub.2007.10.053

Whitaker-Azmitia, P. M. (1999). The discovery of serotonin and its role in neuroscience. Neuropsychopharmacology 21, 2S-8S. doi: 10.1016/S0893133X(99)00031-7
Zakharov, I. S., Ierusalimsky, V. N., and Balaban, P. M. (1995). Pedal serotonergic neurons modulate the synaptic input of withdrawal interneurons of Helix. Invert. Neurosci. 1, 41-52. doi: 10.1007/BF02331831

Conflict of Interest Statement: The authors declare that the research was conducted in the absence of any commercial or financial relationships that could be construed as a potential conflict of interest.

Copyright (c) 2015 Andrianov, Bogodvid, Deryabina, Golovchenko, Muranova, Tagirova, Vinarskaya and Gainutdinov. This is an open-access article distributed under the terms of the Creative Commons Attribution License (CC BY). The use, distribution or reproduction in other forums is permitted, provided the original author(s) or licensor are credited and that the original publication in this journal is cited, in accordance with accepted academic practice. No use, distribution or reproduction is permitted which does not comply with these terms. 